\title{
A Case Study of Performance of ICICI Pru. Life Insurance Co. Ltd.
}

\author{
Rupa Gupta*
}

Department of Management Studies, GLA University, Mathura, U.P. India

Email Id:drrupagupta20@gmail.com

\begin{abstract}
Till 1999, the LIC of India has a monopoly in the insurance sector, but after the constitution of IRDA, many private Insurance companies came into this field. ICICI Pru. Life Insurance Co. Ltd. is a giant co. I am working in the private sector. It was set up by 24 Nov. 2000. Since 2000, it has been performing well and maintaining the No. 1 position as a private insurer in the insurance sector. In this research paper, the Performance of ICICI Pru. Life Insurance Co. Ltd. has been analyzed through a measure of technical insolvency and growth to check out the reason behind its successful journey.

Keywords: ICICI Pru. Life Insurance Co. Ltd, IRDA.
\end{abstract}

PAPER/ARTICLE INFO RECEIVED ON: $15 / 2 / 2020$ ACCEPTED ON: 29/3/2020

Reference to this paper should be made as follows:

Rupa Gupta (2020), “A Case Study of Performance of ICICI Pru. Life Insurance Co. Ltd.", Int. J. of Trade and Commerce-IIARTC, Vol. 9, No. 1, pp. $121-127$ 
A Case Study of Performance of ICICI Pru. Life Insurance Co. Ltd.

Rupa Gupta

\section{INTRODUCTION}

Many private players came into the insurance business after the constitution of IRDA. IRDA (Insurance Regulatory Development Authority) was formed after the recommendations of the Malhotra Committee, headed by R. N. Malhotra, who was the governor of RBI in 2000.It regulates the insurance sector all over the world. The first private player, ICICI Prudential Life Insurance Co. Ltd., was the first individual player in the insurance sector of India, has been maintaining excellent popularity amongst its clients. The company offers a muster of policies to suit all sorts of needs of insurers and has a good claim settlement ratio of over $96 \%$.

\section{OBJeCtives OF THE STUDY}

1. To check the growth analysis of ICICI Pru. Life Insurance Co. Ltd.

2. To check the technical insolvency of ICICI Pru. Life Insurance Co. Ltd.

3. To check the liquid position of ICICI Pru. Life Insurance Co. Ltd.

\section{Research Methodology}

Secondary data has been used to measure the performance with the help of annual reports published by ICICI Pru. Life Insurance Co. Ltd. regularly. The data has been taken from 20132014 to 2019-20. Data has been analyzed, tabulated, and personalized and widely used the geometric mean to calculate the annual compound growth rate.

Table-I: Premium received by ICICI Pru. Life Insurance Co. Ltd.:2013-14 to 2019-20.

\begin{tabular}{|c|c|c|}
\hline Year & Amount('000) & Percentage \\
\hline $2013-14$ & 124286495 & 100 \\
$2014-15$ & 153066175 & 123 \\
$2015-16$ & 191643909 & 154 \\
$2016-17$ & 223540020 & 180 \\
$2017-18$ & 270687692 & 218 \\
$2018-19$ & 309297742 & 249 \\
$2019-20$ & NA & NA \\
\hline
\end{tabular}

Source: Annual reports of ICICI Pru. Life Insurance Co. Ltd. Due to the pandemic situation, annual statements of 2019-20 has not been audited, so it is not published and allowed to research Table-I shows the premium received by ICICI Pru. Life insurance co. Ltd is continuously increasing over the years. In absolute terms, the premium received by ICICI is 124286495 thousand in 2013-14 within India, which is growing continually and reaches up to309297742 thousand in 2018-19.Its geometric growth rate is $16.3 \%$ due to its better performance and its goodwill. It has maintained no. 1 position due to its increasing revenues.

Table-II: Commission paid by ICICI Pru. Life Insurance Co. Ltd.:2013-14 to 2019-20.

\begin{tabular}{|c|c|c|}
\hline Year & Amount('000) & Percentage \\
\hline $2013-14$ & 6274850 & 100 \\
$2014-15$ & 5531723 & 88 \\
$2015-16$ & 6199768 & 99 \\
$2016-17$ & 7589160 & 121 \\
$2017-18$ & 14032736 & 224 \\
$2018-19$ & 15512890 & 247 \\
$2019-20$ & NA & NA \\
\hline
\end{tabular}

Source: Annual reports of ICICI Pru. Life Insurance Co. Ltd. Due to the pandemic situation, annual statements of 2019-20 has not been audited, so it is not published and allowed to research Table-II indicates that the commission paid by ICICI Pru. Life Insurance Co. Ltd. is worth Rs. 6274850 thousand in 2013-14, which has been decreased up to 5531723 thousand in 2014-15. It is

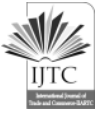


an indicator of the down situation of the business, but it was improved in 2015-16. After that, it had continuously increased by $21 \%$ in 2016-17. In 2018-19 it was recorded a very high upward ratio by $147 \%$, which is an indicator of its growing business.

Table-III: Operating Exp. Related to Insurancebusiness:2013-14 to 2019-20.

\begin{tabular}{|c|c|c|}
\hline Year & Amount('000) & Percentage \\
\hline $2013-14$ & 16168605 & 100 \\
$2014-15$ & 16520225 & 102 \\
$2015-16$ & 18883489 & 117 \\
$2016-17$ & 23571961 & 146 \\
$2017-18$ & 20299312 & 126 \\
$2018-19$ & 26053211 & 161 \\
$2019-20$ & NA & NA \\
\hline
\end{tabular}

Source: Annual reports of ICICI Pru. Life Insurance Co. Ltd. Due to the pandemic situation, annual statements of 2019-20 has not been audited, so it is not published and allowed to research Table-III indicates the operating Exps of ICICI Pru. Life Insurance Co. Ltd. is continuously increasing over the years. In 2013-14, it was 16168605 thousand, which were reached in 23571961 thousand in 2016-17.It was not a good sign of business because increasing operating expenses is the reason for decreasing profitability, but this situation was under control in 2017-18.In 2017-18 the ratio of operating expense. Is decreasing up to $20 \%$, which shows effective management control over operating expenses.Again2018-19, it has been increased by 35\%.

Table-IV: Benefits Paid by ICICI Pru. Insurance Co. Ltd.: 2013-14 to 2019-20.

\begin{tabular}{|c|c|c|}
\hline Year & Amount('000) & Percentage \\
\hline $2013-14$ & 121573359 & 100 \\
$2014-15$ & 123525545 & 102 \\
$2015-16$ & 125419812 & 103 \\
$2016-17$ & 151351253 & 124 \\
$2017-18$ & 174908162 & 144 \\
$2018-19$ & 145558270 & 120 \\
$2019-20$ & NA & NA \\
\hline
\end{tabular}

Source: Annual reports of ICICI Pru. Life Insurance Co. Ltd. Due to the pandemic situation, annual statements of 2019-20 has not been audited, so it is not published and allowed to research Table-IV indicates that benefits paid by ICICI Pru. Life Insurance Co. Ltd is continuously increasing up to 2017-18. It has been recorded an annual compound growth rate of 7.5\%. It shows that it is paying its obligations timely, which is an indicator of its technical insolvency. But It was decreasing by $24 \%$ in $2018-19$.

“Table-V: Claims Paid by ICICI Pru. Life Insurance Co. Ltd. 2013-14 to 2019-20"

\begin{tabular}{|c|c|c|c|c|}
\hline Year & By Death('000) & Percentage & By Maturity('000) & Percentage \\
\hline $2013-14$ & 3660541 & 100 & 2034296 & 100 \\
$2014-15$ & 4019561 & 110 & 3150613 & 155 \\
$2015-16$ & 4792017 & 131 & 4907362 & 241 \\
$2016-17$ & 5912549 & 162 & 22829969 & 1122 \\
$2017-18$ & 8641145 & 236 & 33584374 & 1651 \\
$2018-19$ & 10939284 & 299 & 22735868 & 1118 \\
$2019-20$ & NA & NA & NA & NA \\
\hline
\end{tabular}

Source: Annual reports of ICICI Pru. Life Insurance Co. Ltd. Due to the pandemic situation, annual statements of 2019-20 has not been audited, so it is not published and allowed to research Table-V indicates that claims paid by ICICI Pru. Life Insurance Co. Ltd is continuously increasing over the years. Claims paid by death accounted an annual compound growth rate by $20 \%$ upto 
A Case Study of Performance of ICICI Pru. Life Insurance Co. Ltd.

Rupa Gupta

2018-19\& claims paid by maturity accounted a yearly compound growth rate by $75.2 \%$ upto 201718.but maturity claims has been decreased in $2018-19$ by $533 \%$ It is paying claims by maturity more than claims paid by death. It also shows its technical insolvency, which is a remarkable component of its goodwill. It shows another fact also that people have increased their death age due to growing medical facilities, effective solutions given by the govt. of poor people.

"Table-VI: Annuities paid by ICICI Pru. Life Insurance Co. Ltd.: 2013-14 to 2019-20."

\begin{tabular}{|c|c|c|}
\hline Year & Amount('000) & Percentage \\
\hline $2013-14$ & 952368 & 100 \\
$2014-15$ & 1126588 & 118 \\
$2015-16$ & 1270916 & 133 \\
$2016-17$ & 1389762 & 146 \\
$2017-18$ & 1522440 & 160 \\
$2018-19$ & 1769109 & 186 \\
$2019-20$ & NA & NA \\
\hline
\end{tabular}

Source: Annual reports of ICICI Pru. Life Insurance Co. Ltd. Due to the pandemic situation, annual statements of 2019-20 has not been audited, so it is not published and allowed to research Table-VI indicates that annuities paid by ICICI Pru. Life Insurance Co. Ltd is continuously increasing over the years. Pensions accounted for an annual compound growth rate of $10.09 \%$.Annuities mean yearly payment, which has been paid regularly besides claims and other obligations. It also shows its technical insolvency, which is a remarkable component of its goodwill.

“Table-VII: Surrender Paid by ICICI Pru. Life Insurance Co. Ltd.:2013-14 to 2019-20."

\begin{tabular}{|c|c|c|}
\hline Year & Amount('000) & Percentage \\
\hline $2013-14$ & 113065833 & 100 \\
$2014-15$ & 113096640 & 100 \\
$2015-16$ & 112067294 & 99 \\
$2016-17$ & 117940746 & 104 \\
$2017-18$ & 127606473 & 112 \\
$2018-19$ & 106115264 & 94 \\
$2019-20$ & NA & NA \\
\hline
\end{tabular}

Source: Annual reports of ICICI Pru. Life Insurance Co. Ltd. Due to the pandemic situation, annual statements of 2019-20 has not been audited, so it is not published and allowed to research Table -VII indicates that surrenders paid by ICICI Pru. Life Insurance Co. Ltd. is a constant upto 2015-16. After that, it has been increased by 117940746 thousand in 2016-17 and reached up to 127606473 thousand in 2017-18, which is not a good sign for the company because it shows the distrust of policyholders regarding ICICI Pru. Life Insurance Co. Ltd. Many other reasons can also be existed to surrender their policy, such as financial problems, the increasing competition of other private insurers. It has been declined upto 106115264 thousand in 2018-19.It is a suitable remark for its efforts.

“Table-VIII: Reserve \& Surplus: 2013-14 to 2019-20"

\begin{tabular}{|c|c|c|}
\hline Year & Amount('000) & Percentage \\
\hline $2013-14$ & 33663847 & 100 \\
$2014-15$ & 34320453 & 102 \\
$2015-16$ & 36415012 & 108 \\
$2016-17$ & 46996096 & 140 \\
$2017-18$ & 51408643 & 153 \\
$2018-19$ & 54353450 & 161 \\
$2019-20$ & NA & NA \\
\hline
\end{tabular}


Source: Annual reports of ICICI Pru. Life Insurance Co. Ltd.Due to the pandemic situation, annual statements of 2019-20 has not been audited, so it is not published and allowed to research Table -VIII indicates that reserve \& Surplus of ICICI Pru. Life Insurance Co. Ltd is continuously increasing over the years. It is a good indicator of its financial strength. Its geometric growth rate is $8.2 \%$, which shows its power.The company is maintaining reserve \& surplus besides paying their liabilities. It is a good sign of its profitability. Company plans are more comprehensive for their expansions.

"Table-IX: Fixed Assets of ICICIPru. Life Insurance Co. Ltd.: 2013-14 to 2019-20."

\begin{tabular}{|c|c|c|}
\hline Year & Amount('000) & Percentage \\
\hline $2013-14$ & 2015439 & 100 \\
$2014-15$ & 2149900 & 107 \\
$2015-16$ & 2195346 & 109 \\
$2016-17$ & 2137759 & 106 \\
$2017-18$ & 4220622 & 209 \\
$2018-19$ & 4757022 & 236 \\
$2019-20$ & NA & NA \\
\hline
\end{tabular}

Source: Annual reports of ICICI Pru. Life Insurance Co. Ltd. Due to the pandemic situation, annual statements of 2019-20 has not been audited, so it is not published and allowed to research Table-IX shows ICICI Pru. Life Insurance Co. Ltd. has invested a significant amount in fixed assets. It has invested worth Rs 2015439 thousand in fixed assets in 2013-14, which has been increased up to2195346 thousand in 2015-16. In 2016-17 it was declined up to 2137759 thousand, but next year it has been increased rapidly by double growth rate. It is an excellent signal of its successful journey.

Table-X: Current Assets of ICICI Pru. Life Insurance Co. Ltd.: 2013-14 to 2019-20.

\begin{tabular}{|c|c|c|}
\hline Year & Amount('000) & Percentage \\
\hline $2013-14$ & 9642058 & 100 \\
$2014-15$ & 12328015 & 128 \\
$2015-16$ & 12750803 & 132 \\
$2016-17$ & 26483897 & 275 \\
$2017-18$ & 25102587 & 260 \\
$2018-19$ & 26760967 & 278 \\
$2019-20$ & NA & NA \\
\hline
\end{tabular}

Source: Annual reports of ICICI Pru. Life Insurance Co. Ltd.Due to the pandemic situation, annual statements of 2019-20 has not been audited, so it is not published and allowed to research Table -X shows the current assets of ICICI Pru. Life Insurance Co. Ltd. has been continuously increasing over the years. In 2013-14 it was 9642058 thousand, which were reached up to 26483897 thousand in 2016-17. But in 2017-18, it has recorded a slightly downward slope by $15 \%$. But in 2018-19 it is increased by 18\%.Overall its liquidity position is good.

“Table-XI: Cash \& Bank Balances of ICICI Pru. Life Insurance Co. Ltd.: 2013-14 to 2019-20."

\begin{tabular}{|c|c|c|}
\hline Year & Amount('000) & Percentage \\
\hline $2013-14$ & 1934384 & 100 \\
$2014-15$ & 2554800 & 132 \\
$2015-16$ & 2002062 & 103 \\
$2016-17$ & 2136956 & 110 \\
$2017-18$ & 2037435 & 105 \\
$2018-19$ & 6610406 & 341 \\
$2019-20$ & NA & NA \\
\hline
\end{tabular}


A Case Study of Performance of ICICI Pru. Life Insurance Co. Ltd.

Rupa Gupta

Source: Annual reports of ICICI Pru. Life Insurance Co. Ltd. Due to the pandemic situation, annual statements of 2019-20 has not been audited, so it is not published and allowed to research Table-XI shows that the location of the cash and bank balances of ICICI Pru. Life Insurance Co. Ltd is fluctuating between 100 to 341.In 2013-14, its cash \& bank balances were 1934384 thousand, but in 2018-19 it was reached up to the highest level worth Rs. 6610406 thousand. It shows its better performance.

"Table-XII: Loan of ICICI Pru. Life Insurance Co. Ltd.: 2013-14 to 2019-20."

\begin{tabular}{|c|c|c|}
\hline Year & Amount('000) & Percentage \\
\hline $2013-14$ & 119076 & 100 \\
$2014-15$ & 201121 & 169 \\
$2015-16$ & 442718 & 372 \\
$2016-17$ & 806448 & 677 \\
$2017-18$ & 1450588 & 1218 \\
$2018-19$ & 2701858 & 2269 \\
$2019-20$ & NA & NA \\
\hline
\end{tabular}

Source: Annual reports of ICICI Pru. Life Insurance Co. Ltd.Due to the pandemic situation, annual statements of 2019-20 has not been audited, so it is not published and allowed to research Table-XII shows theLoans of ICICI Pru. Life Insurance Co. Ltd has been continuously increasing by an annual compound growth rate of $68.2 \%$. It is not a good signal for its liquidity.It indicates that the company is working under the high pressure of loan burden, whereas its profitability is increasing by $16.3 \%$.It shows that the company is working with tall gearing.

"Table-13: Current Liabilities of ICICI Pru. Life Insurance Co. Ltd.: 2013-14 to 2019-20."

\begin{tabular}{|c|c|c|}
\hline Year & Amount('000) & Percentage \\
\hline $2013-14$ & 16066435 & 100 \\
$2014-15$ & 17781603 & 111 \\
$2015-16$ & 18213785 & 113 \\
$2016-17$ & 28157262 & 175 \\
$2017-18$ & 34254125 & 213 \\
$2018-19$ & 36388912 & 226 \\
$2019-20$ & NA & NA \\
\hline
\end{tabular}

Source: Annual reports of ICICI Pru. Life Insurance Co. Ltd.Due to the pandemic situation, annual statements of 2019-20 has not been audited, so it is not published and allowed to research Table-XIII shows that current liabilities of ICICI Pru Life Insurance Co. Ltd. have been continuously increasing by an annual compound growth rate of $14.6 \%$. It is not a good signal for its liquidity.It indicates that the company is working under the optimal balance of its growth and its liabilities because its profitability is increasing by $16.3 \%$ and itsdebt is growing by $14.6 \%$.

\section{LIMITATIONS OF THE STUDY}

Due to a shortage of time and certain restrictions, the comparison of ICICI Pru. Life Insurance Co. Ltd. with other Insurance Companies could not be done. Already ICICI Pru. Life Insurance Co. Ltd is the largest company working in the private sector in the Insurance Industry. Since the study is based upon secondary data, hence the result will depend on these data.

\section{FINDINGS AND SUGGESTIONS}

ICICI Pru. Life Insurance Co. Ltd. has remarked the annual compound growth rate by $16.3 \%$ within India. It is spreading its business through its agents, brokers. It is continuously paying commission for direct business and reinsurance business. Any organization can increase their profitability by curtailing their operating expenses. ICICI Pru. Life Insurance Co. Ltd. has not

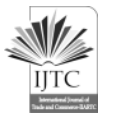


been maintaining reasonable control over its operating expenses for2016-17. Its operating cost is continuously increasing. It is not a good indicator of their better performance. It has been paying its obligations such as claim paid by maturity, demand paid by death, annuities, etc. correctly, which shows that its technical insolvency is very high. Its financial strength is also good. It has not been maintaining its customer retention ratio because of surrender values given by ICICI. Now LIC of India and other Private insurers are giving more emphasis on advertising and building brand awareness through different modes of communication in comparison to ICICI Pru. Life Insurance Co. Ltd. ICICI Pru. Life Insurance Co. Ltd. should come up with new innovative products to offer a greater variety of choices to the customers and also make improvements in the quality of services and sell products through appropriate distribution channel to face the increasing situation of competition. The upcoming products having features with high-risk cover, more return and low insurance premium will be helpful to attract more number of customers.

ICICI Pru should consider another feature. Life Insurance Co. Ltd. is that the terms and conditions of the product should be transparent to the public. Giving Relaxation in the formalities to renew lapsed policies will play an essential role in reducing their surrender ratio, and it will capture the market again from those policyholders who have switched in another investment option. For this, a Periodical review about the service quality is required to maintain and improve the service quality.

\section{Conclusion}

ICICI Pru. Life Insurance Co. Ltd. has proved that its financial position is perfect, technical insolvency is also better because it is paying their obligations timely. It should curtail its operating expense. To increase their profitability. No doubt, its future is so bright due to its financial strength, better technical insolvency, ethical behavior, and dedication towards their policyholders. Service quality can be used as a strategic tool to get a competitive advantage over challenging insurance providers. ICICI Pru. Life Insurance Co. Ltd. should focus on assurance and tangibility to further strengthen the level of service quality. ICICI Pru. Life Insurance Co. Ltd. competes with other private players as well as LIC of India in the market very aggressively. Still, the low score in the reliability dimension is a contra indicator.

\section{REFERENCES}

[1]. Gupta, R., and Varshney, S.C. (2012). Performance Appraisal-A Comparative study of LIC of India and ICICI Pru. Life Insurance Company: Southern Economist, 51(14), 29-34.

[2]. Gupta, R., and Varshney, S.C. (2012). Customer Satisfaction-A Comparative study of LIC of India and ICICI Prudential Life Insurance Company Ltd.: International Journal of Commerce and Management, 2(2), 11-17.

[3]. Annual Reports of ICICI Pru. Life Insurance Co. Ltd.

[4]. WWW.IRDA.Com 